\title{
Estimating car use rebound effects from Swedish microdata
}

\author{
David Andersson (iD • Ross Linscott • Jonas Nässén (i)
}

Received: 1 October 2018 / Accepted: 21 August 2019 /Published online: 27 November 2019

(C) The Author(s) 2019

\begin{abstract}
The direct rebound effect for private car transport was estimated by following a large sample of Swedish households $(28,876)$ that acquired a new car in 2009. For some households, this resulted in an improvement in fuel efficiency, whereas others acquired a less or similarly fuel efficient car. The households' travel distances were measured and analysed for a period of 3 years before and 3 years after the car was replaced. This approach differs from previous econometric analyses in which fleet-average changes in distance travelled were studied, often using fluctuations in fuel cost as a proxy for changes in fuel efficiency. No significant bivariate relationship was found between changes in fuel efficiency and annual distance travelled but a multivariate analysis that also included changes in income, number of cars in the household, car weight and car power, resulted in a significant rebound effect of $24 \%$. Households who bought a car that was labelled 'green' did not exhibit any rebound effect, while households who bought a 'normal' car displayed a rebound effect of $32 \%$. This could indicate that households that buy a car with improved fuel efficiency for environmental reasons also avoid the economically induced rebound effect. The analysis did not indicate any significant
\end{abstract}

D. Andersson

Department of Psychology, University of Gothenburg, PO Box 500, SE-40530 Gothenburg, Sweden

R. Linscott · J. Nässén $(\square)$

Division of Physical Resource Theory, Chalmers University of

Technology, SE-41269 Gothenburg, Sweden

e-mail: jonasna@chalmers.se differences in the rebound effect between different sociodemographic groups.

Keywords Fuel efficiency · Rebound effect · Cars · Sweden

\section{Introduction}

Improving energy efficiency has often been identified as a key strategy for climate change mitigation (Pacala and Socolow 2004; OECD/IEA 2017). But doubts have also been raised about the extent to which energy efficiency can reduce environmental impacts since improvements in efficiency may 'rebound' as a result of increasing consumption. There are at least three potential mechanisms behind rebound effects. First, energy-efficient technologies reduce the marginal cost of the energy services they provide and may therefore result in increasing energy service demand. For example, a household buying a fuel efficient car will face lower marginal costs per kilometre and could hence be expected to drive longer distances. This mechanism is referred to as the direct rebound effect. Second, energy efficiency improvements may cause indirect rebound effects, since money saved by reducing fuel consumption can be used to increase expenditure on other products and services. A third mechanism occurs at the economy-wide level, where a reduction in energy demand may result in lower prices for both energy and products with energy inputs, which in turn causes increasing energy demand through consumption by other households and companies 
(Greening et al. 2000, Sorrell and Dimitropoulos 2008). In this paper, we address the direct rebound effect of private automotive transport.

Sorrell et al. (2009) provide a comprehensive review of empirical estimates of the direct rebound effect for personal transport and residential energy use. For private automotive transport, this literature consists of studies that have applied different types of econometric methods utilising data sets on energy use, distances travelled and prices in the form of time series (Blair et al. 1984; Mayo and Mathis 1988; Gately 1992; Greene 1992; Jones 1993; Schimek 1996); crosssectional comparisons of countries, states or households (Wheaton 1982; Greene et al. 1999; West 2004); or panels that make use of both temporal and crosssectional variations (Haughton and Sarkar 1996; Goldberg 1998; Wirl 1997; Schipper and Johansson 1997; Puller and Greening 1999; Small and Van Dender 2005; Frondel et al. 2008). Estimates of longterm direct rebound effects from these studies range from 3 to $87 \%$ with a median estimate of around $25 \%$.

One problem with these econometric approaches is that the historical variation in fleet-average fuel consumption per kilometre has been relatively small. Therefore, most of these studies have relied on the assumption that the direct rebound effect can be estimated by the elasticity of distance travelled with respect to the fuel cost per kilometre. Some studies have also estimated the rebound effect as the negative of the own-price elasticity of energy. Since the own-price elasticity would also capture the influence of energy prices on energy efficiency, such estimates may provide an upper boundary for the direct rebound effect. Examples of studies using this proxy include Freire-Gonzalez (2010), Wang et al. (2012) and Moshiri and Aliyev (2017) all arrive at relatively high estimates. The basic assumption behind this approach is that people ought to respond to improvements in fuel efficiency in the same way as they do to a change in the price of fuel. However, some people who purchase fuel efficient cars may do so with a more straightforward objective of reducing fuel costs or greenhouse gas emissions. Why then would they start driving more to the same extent as the general public does when oil prices go down? The prominence given to changes in fuel prices, particularly considering the media attention during periods of rapid price rises and price volatility, may also trigger psychological and social mechanisms other than fuel efficiency. Previous studies by Small and Van Dender (2007), Greene (2012) and
Stapleton et al. (2016) all found significant rebound effects when the fuel cost per kilometre was used as a proxy, while none of them found significant effects with respect to actual fuel consumption per kilometre.

Another problem seen in previous studies is that a correlation between fuel efficiency and travel demand may not necessarily be caused by a rebound effect, i.e. that improvements in fuel efficiency cause an increase in travel demand. The causation might just as well go in the other direction, since increasing distances travelled will make investments in fuel efficiency more profitable. This 'endogeneity' of fuel efficiency could imply that several studies have overestimated the direct rebound effect. Moreover, the omission or inclusion of other factors may also affect estimates. Since as many as 12 of the 16 studies reviewed by Sorrell et al. (2009) have used data sets from the USA, an example of an important factor in previous estimates might be the implementation of the CAFE regulation in 1978, which had a significant impact on fuel efficiency and its relationship to fuel prices. Different econometric studies have either omitted CAFE or suggested different approaches to account for it in their models (Schimek 1996; Haughton and Sarkar 1996; Small and Van Dender 2007).

In this study, we attempt to analyse the direct rebound effects by following the distances travelled by individual households over time. How do people change the distances they travel after acquiring a car with improved fuel efficiency? This direct approach captures the most common (pedagogical) description of the mechanism behind the direct rebound effect, for example as exemplified in the introduction of Sorrell et al. (2009) that '[...] consumers may choose to drive further and/or more often following the purchase of a fuel-efficient car because the operating cost per kilometre has fallen.' By means of the Swedish car registry, we carried out a longitudinal analysis of annual distances travelled for 28,876 individual households that changed their car in 2009 either from low to high fuel efficiency or vice versa. To our knowledge, there is only one previous study that has approached the rebound effects of private automotive travel in a similar way. De Borger et al. (2016) analysed a large data set of individual Danish households and arrived at a relatively low estimate of the rebound effect, in the range 7.5-10\%. In addition, Frondel et al. (2012) also analysed 2165 households from the German Mobility Panel 1997-2009 and found high estimates of direct rebound effects in the range of $57 \%$ to $62 \%$. However, as opposed to our sample and 
the sample used in De Borger et al. (2016), the German sample only included a very limited number of households that appeared in more than 1 year in the data; hence, relatively few actual car changes were included.

\section{Methodology and data}

As stated in the introduction, this study employed a partially new approach to measuring the direct rebound effect for personal automotive transport. We followed all Swedish households who replaced their car in 2009, and compared distances travelled before and after the replacement took place. Our data set included fuel consumption per kilometre before and after the change of vehicle together with other variables related to the households and their cars.

We looked at absolute differences between the two time periods for various variables and modelled the change in household distance travelled in a linear regression model. Using the coefficient for the change in fuel efficiency factor, we were able to construct an estimate of the rebound effect. The rebound effect (RE) is defined as the percentage change in distance travelled $D$ per percentage change in fuel efficiency $E$ (see Equation 1). The following sections describe the database and sample selection ('Database and sample selection'), the sample representativity ('Sample representativity'), the multivariate model and model variables ('Model specification') and a model that corrects for the increasing gap between the standardised type-approval fuel consumption estimates and actual fuel consumption per kilometre ('Adjusting type-approved values to realworld fuel consumption').

$R E=\frac{\partial D / D}{\partial E / E}$

Database and sample selection

Data for the analysis were collected from Statistics Sweden's Microdata Online Access database (MONA) which compiles all registry data collected by different government agencies. The MONA database offers information on car make and model, model year, fuel type, type-approved fuel consumption as measured by the NEDC (New European Driving Cycle) and odometer readings. Yearly driving distance was estimated from the two adjacent odometer readings and adjusted to fullyear equivalents. Cars that did not run on conventional fuels such as petrol, diesel or ethanol were removed from the sample. We also excluded cars with no registered driving distance. Information on fuel consumption, weight and power for cars produced before 2000 were not included in the MONA database, and were instead obtained from a separate database covering older cars (Sprei and Karlsson 2013).

The sample consisted of all Swedish households who owned at least one car between 2007 and 2009, replaced at least one car in 2009 and owned it until 2012 (a total of 225,431 households, households with a company car were excluded from the sample). The 3-year period after the change of car was included since there is no mandatory vehicle inspection in the first 3 years for new cars and hence no odometer data on driving distance.

We assigned to each household a value for each carrelated variable equal to the mean of this variable over all cars owned by each household, weighted by the distance driven with each car. If data were missing for any car owned by the household, or the household only owned cars which were filtered out of the data set in either period, the household was removed from the sample (90,205 households were removed).

Household characteristics such as the number of adults and children, employment-related income and any parental benefits during the two periods were collected from the MONA database, as well as unique identifiers for the location of home and workplace and whether households were living in a densely or sparsely populated area. A further 19,264 households with no registered employment-related income were removed since it is likely that they have some alternative source of income which is not included in the registry.

To avoid the endogeneity which would be caused by households choosing a new car in relation to planning to move to a new house or switch to a new job, we removed from the sample all households who did either of these things (86,225 households).

The data set also contained some outliers and we chose to exclude the top and bottom 0.5 percentiles of the data in the two dimensions income and distance travelled in both the before and after data sets. A total of 861 households were removed due to these criteria. This left us with a final sample of 28,876 households. The successive exclusion rules and the following attrition of data are summarized in Table 1. 
Table 1 Sample selection and exclusion

\begin{tabular}{ll}
\hline Criterion & $\begin{array}{l}\text { Remaining } \\
\text { households } \\
(N)\end{array}$ \\
\hline $\begin{array}{l}\text { Households with } \geq 1 \text { car who replaced } \geq 1 \\
\quad \text { car in 2009 }\end{array}$ & 225,431 \\
$\begin{array}{l}\text { Households where any car data were missing or where } \\
\quad \text { cars run on unconventional fuels were excluded }\end{array}$ & 135,226 \\
$\begin{array}{l}\text { Households with unemployed household members } \\
\quad \text { excluded }\end{array}$ & 115,962 \\
$\begin{array}{l}\text { Households who moved or changed workplace excluded } \\
\text { Outliers excluded }\end{array}$ & 29,737 \\
Main sample & 28,876 \\
& 28,876 \\
\hline
\end{tabular}

Sample representativity

Sorrell et al. (2009) found 12 studies with an approach to direct rebound effects similar to ours but applied to household heating, and listed some potential problems associated with this approach. According to Sorrell et al. (2009), due to the limited availability of pre and post data sets, this approach often leads to small sample sizes, a lack of control groups and risk of selection bias. The Swedish car registry is quite satisfactory in that it enabled us to include all households in Sweden that replaced their car during the studied period, thereby avoiding the pitfalls of using a small sample size. The issue of including a control group is more problematic however, since by definition only households who have acquired a different car are of interest to measuring the direct rebound effect. By defining the sample population as households who replaced their car in a given year, any characteristics specific for this group could cause a selection bias and hence affect the generalisability of our results. We therefore compared age- and employment-related income in our final sample with all Swedish car owners over 23 years of age in 2012 $(N=2,408,023)$. Individuals included in the sample had to already own a car in 2007 , and the youngest car owner in the 2012 sample was 23 years old. The final sample in 2012 had an average age of 51.6 years and earned SEK 343,000 SEK per year before taxes, while the corresponding figures for the entire population of car owners in Sweden are 47.9 years and SEK 333,000. Our final sample is thus somewhat older and has a slightly higher employment-related income on average, compared to the average in the Swedish population of car owners. We also compared the change in driving distances for our sample to the aggregated changes in
Sweden. While our sample of car buyers increased their driving distance by on average $2 \%$ in the studied period, the average Swede reduced car driving by $3 \%$. This difference is expected since buying a car is linked to a need for car usage.

Model specification

Equation (2) models the relationship between distance travelled $(D)$ and fuel efficiency $(E)$, income $(I)$, number of cars $(C)$, car weight $(W)$ and car power $(P)$. Delta $(\Delta)$ indicates the absolute difference between the after (20092012) and before (2005-2008) periods, and $D_{0}$ is the distance travelled in the before period. Each variable is a household level aggregate. Fuel efficiency, car weight and car power are household averages weighted by car driving distance, and fuel efficiency is measured in kilometres per litre and adjusted from specification values as described below. The income and number of cars variables are the sum for the household. Fuel price is not explicitly included in the model since all households experienced (nearly) the same change in fuel price over the period. This means that a potential price effect will be captured by the offset coefficient $\left(\beta_{6}\right)$.

$$
\begin{aligned}
\Delta D=\alpha \Delta E & +\beta_{1} D_{0}+\beta_{2} \Delta I+\beta_{3} \Delta C+\beta_{4} \Delta W \\
& +\beta_{5} \Delta P+\beta_{6}+\varepsilon
\end{aligned}
$$

The driving distance baseline factor $\left(D_{0}\right)$ was included to control for regression to the mean. Households that happened to drive long distances in the baseline year (say due to a specific car-based holiday) are also more likely to reduce distances travelled in the following years for this very reason.

The change in income factor $(\Delta I)$ was included to control for a change in the households' purchasing power, which according to some previous studies may influence the rebound effect because low-income households could be assumed to be further from satiation in their consumption (Milne and Boardman 2000; Chitnis et al. 2014).

The change in number of cars factor $(\Delta C)$ was included to control for behavioural changes that might arise when a household gains or loses different driving options depending on the number of cars they own.

The change in car weight $(\Delta W)$ and change in car power $(\Delta P)$ factors were included so that we can distinguish variables related to driving characteristics such as comfort and performance from 
fuel efficiency. For example, one might expect that a household that expects to drive more in the future may also prefer switching to a more comfortable car. Without including a factor linked to car comfort, this would show as a negative rebound effect, since more comfortable cars tend to be less fuel efficient. By including weight and power, we can separate this effect from the rebound effect.

The intercept term is included to control for general trends which affect all households, such as changes in fuel prices, general trends in driving habits and effects from the development of roads and infrastructure. The car data used in the model are summarized in Table 2.

In order to compare our estimates to previous estimates of the rebound effect (as defined in Equation (1)), we normalise by a factor equal to the ratio between the averages of fuel efficiency and distance travelled in the sample used, according to Equation (3) as follows:

$\Delta D=\alpha \Delta E+r e m \Rightarrow \alpha=\frac{\partial D}{\partial E} \Rightarrow R E \approx \frac{\bar{E}}{\bar{D}} \alpha$

Coefficients were estimated using OLS regression, and we noted that the residuals had a distribution with somewhat heavier tails than what would be expected in a normal distribution. We also found a significant deviation from the normal distribution according to the Shapiro-Wilk's normality test. This indicates that the standard $t$ test will overestimate significance; we therefore supplemented the $t$ test with wild bootstrap confidence intervals using the Rademacher residual scaling (see Flachaire 2005). With this procedure, we were able to estimate the variance in the rebound estimate by resampling the measured residuals rather than using quantiles of some theoretical distribution. This gives us a confidence interval for the rebound effect estimate that is not dependent on the residuals following from a specific distribution.

A number of different binary group divisions in the sample are investigated by performing the regression separately on each subsample. We adopted the framework of Paternoster et al. (1998) for testing the significance of the difference in the rebound effect between groups, as well as checking overlap of the bootstrapped confidence intervals.

Adjusting type-approved values to real-world fuel consumption

Real-world reported figures of fuel consumption $\left(E_{\mathrm{RW}}\right)$ are typically significantly higher than the manufacturers' type-approval estimates $\left(E_{\mathrm{TA}}\right)$ (this is especially true for the New European Driving Cycle (NEDC) used in Sweden at the time). This discrepancy is also noted by De Borger et al. (2016), and we believe it may significantly impact analysis with models that use NEDC values, since the difference is (1) larger for fuel efficient cars (Ntziachristos et al. 2014), and (2) increasing over time (ICCT 2015). In the following steps, we describe how we adjusted for these differences. Fuel consumption in these expressions follows the standard type-approval unit of litres per $100 \mathrm{~km}$, whereas the fuel efficiency unit in the other analyses of the paper is $\mathrm{km}$ per litre of petrol-eq. so that a high efficiency results in low fuel consumption.

As the first step, we used the results from Ntziachristos et al. (2014) on how $E_{\mathrm{RW}}$ is related

Table 2 Summary of car use statistics

\begin{tabular}{llllll}
\hline Variable & Unit & Before & & \multicolumn{2}{c}{ After } \\
\cline { 3 - 5 } & & Mean & S.D. & Mean & S.D. \\
\hline Driving distance & Kilometres/year & 1904 & 1062 & 1945 & 1094 \\
Fuel efficiency & km/l petrol-eq. & 11.3 & 1.6 & 0.55 & 1.7 \\
No. of cars & - & 1.32 & 198 & 1457 & 0.63 \\
Car weight & Kilogrammes & 1399 & 26.1 & 100.8 & 200 \\
Car power & Kilowatts & 94.7 & & & 27.5 \\
\hline
\end{tabular}


to $E_{\mathrm{TA}}$ for petrol cars (Eq. 4a) and for diesel cars (Eq. 4b).

$$
\mathrm{E}_{\mathrm{RW}}=1.8+0.90 E_{\mathrm{TA}}
$$

$$
\mathrm{E}_{\mathrm{RW}}=1.8+0.88 E_{\mathrm{TA}}
$$

In the second step, we also included an adjustment over time based on the estimate that the divergence between $E_{\mathrm{RW}}$ and $E_{\mathrm{TA}}$ had increased from $8 \%$ in 2001 to $19 \%$ in 2009 (ICCT 2015). This study does not include cars from more recent years, but it is notable that this divergence has increased rapidly to $36 \%$ for private cars in 2014. Since cars have also become increasingly fuel efficient over time, this divergence is partly included in our corrections in Equations $4 \mathrm{a}$ and $4 \mathrm{~b}$. These equations alone would cause an increase in the divergence from 10 to $15 \%$ for petrol cars and from 13 to $16 \%$ for diesel cars between 2001 and 2009. In order to wholly account for the increase in divergence over time, we added a term with the model year $\left(t_{M}\right)$ as shown in Equations $5 \mathrm{a}$ and $5 \mathrm{~b}$.

$$
\begin{aligned}
& \mathrm{E}_{\mathrm{RW}}=1.5+0.90 E_{\mathrm{TA}}+0.060\left(t_{M}-2000\right) \\
& \mathrm{E}_{\mathrm{RW}}=1.4+0.88 E_{\mathrm{TA}}+0.061\left(t_{M}-2000\right)
\end{aligned}
$$

When estimating the changes in fuel efficiency, we converted $E_{\mathrm{RW}}$ estimates into litres of petrol equivalents based on their energy content. We further assumed that biofuel/flexifuel cars are fuelled with $49 \%$ E85 (85\% ethanol, $15 \%$ petrol) and $51 \%$ petrol (Swedish Transport Administration 2012). Finally, we extrapolated the model backwards in time by assuming that the model year term disappears in the years earlier than 2000 but that the divergence was never lower than $8 \%$, i.e. $E_{\mathrm{RW}}>=1.08 \times E_{\mathrm{TA}}$.

\section{Results}

Bivariate analysis

Figure 1 presents the changes in annual distance travelled and fuel efficiency per $\mathrm{km}$ petrol equivalents between 2008 and 2012 in the sample population. A rebound effect would be seen as an increase in distance travelled for households who have changed to more fuel efficient cars (the two boxes to the right), while the opposite would be true for households who have shifted to less fuel efficient cars (boxes to the left). There is no such tendency and the estimated rebound effect in the entire sample for the bivariate model amounts to $0.38 \%(p=0.83)$. The wild bootstrap $95 \%$ confidence interval suggests that the rebound effect should lie between -4 and $4 \%$, confirming that there is no significant relationship.

Table 3 provides the bivariate correlation matrix for all the studied variables. The same variables will be used in the following multivariate analysis.

Multivariate analysis

Estimating Equation (2) by OLS, we found that all coefficients except the car power coefficient were highly significant $(p<2 \mathrm{e}-16)$, with a rebound effect of $24 \%$ and values according to Table 4 . The wild bootstrap $95 \%$ confidence interval suggests that the rebound effect lies between 17 and $25 \%$. The second column in Table 4 shows estimates based on the subsample of single-car households, which shows similar results. When households who moved or switched workplace between the periods were added to the sample $(n=112,442)$, the estimate of the rebound effect increased to $30 \%$.

We see that while the rebound effect was nonsignificant in the bivariate analyses it clearly emerges in the multivariate analysis. The main explanation for this can be found in the correlation with car size, represented by the variable for car weight $(W)$. As shown by Table 3, buying a larger car is correlated with increasing driving distances. This could either be a planned behaviour because of an anticipated increase in the need for car usage or a behaviour in the specific choices between travel modes, where a larger car meets the functional demands for a larger share of a household's trips. In the same way, buying a smaller car correlates with less driving. Car size, however, is also correlated with fuel efficiency. Changing to a car that is both smaller and more fuel efficient could be expected to lead to less driving due to the functional characteristics of the car but more driving due to the lower variable cost (the rebound effect). In the bivariate analysis, the former effect appears to mask the latter effect. In addition, the bivariate analysis does not account for the regression to the means effect, whereby households who happened to 
Fig. 1 Box plot of change in distance travelled and change in fuel efficiency. The distribution measurements indicate $5 \%$, $25 \%, 50 \%, 75 \%$ and $95 \%$ quantiles. Samples include only households that did not change workplace or housing location

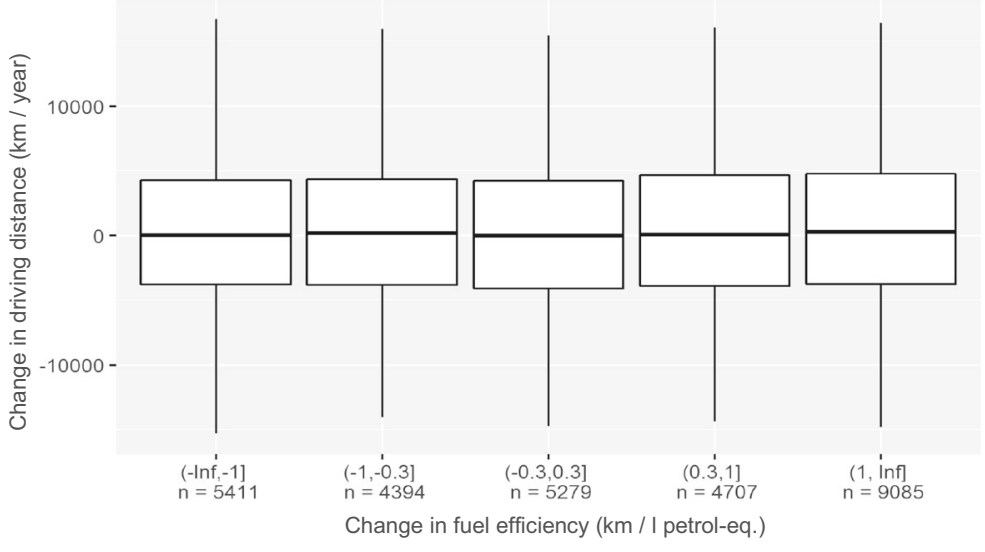

drive a lot in the specific period before the change, for example due to a long vacation trip, will on average reduce their driving and vice versa.

An important data-related feature of this paper is the adjustment of fuel consumption from type-approval to real-world values ('Adjusting type-approved values to real-world fuel consumption'). For comparison, we re-ran the same model for the main sample in Table 4 with the unadjusted fuel consumption values. This resulted in a substantially lower rebound effect of $15 \%$ instead of $24 \%$.

\section{Comparison of socio-demographic groups}

This section describes the rebound effect among different groups. The results are summarised in Table 5. We found that households who bought a car certified as 'green' by the Swedish government $\left(<120 \mathrm{~g} \mathrm{CO}_{2} / \mathrm{km}\right)$ showed no statistically significant rebound effect, while the remaining group had a rebound effect estimate of almost $32 \%$. This result can also explain why we see a smaller effect in the group that increased their fuel efficiency $(13 \%)$ as compared to those who reduced fuel efficiency ( $34 \%$ ) (the latter meaning that households buying a less efficient car also drove less). To corroborate the rather interesting result for households who bought a 'green' car, we also ran the model for households that bought a vehicle with a rather high fuel efficiency of at least $14 \mathrm{~km}$ per litre but that was not labelled as green $(n=958)$. For these households, the rebound effect was estimated to $28 \%$, i.e. very similar to the full group of non-green cars. Hence, the behaviour of green car buyers appears to be significantly different from all other groups of car buyers.

Splits between rural and urban households, between single and multiple member households, and single and multiple car households were also estimated but did not show any significant differences, and neither did any of the income groups.

Table 3 Bivariate Pearson's r correlations for the studied variables

\begin{tabular}{|c|c|c|c|c|c|c|c|}
\hline & $\begin{array}{l}\Delta \text { Driving } \\
\text { distance }\end{array}$ & $\begin{array}{l}\Delta \text { Fuel } \\
\text { efficiency }\end{array}$ & $\begin{array}{l}\text { Driving } \\
\text { distance baseline }\end{array}$ & $\begin{array}{l}\Delta \\
\text { Income }\end{array}$ & $\begin{array}{l}\Delta \text { No. } \\
\text { of cars }\end{array}$ & $\begin{array}{l}\Delta \text { Car } \\
\text { weight }\end{array}$ & $\begin{array}{l}\Delta \text { Car } \\
\text { power }\end{array}$ \\
\hline$\Delta$ Driving distance & 1 & & & & & & \\
\hline$\Delta$ Fuel efficiency & -.001 & 1 & & & & & \\
\hline Driving distance baseline & $-.411^{* * *}$ & $.026^{* * *}$ & 1 & & & & \\
\hline$\Delta$ Income & $.088^{* * *}$ & -.011 & $.066^{* * *}$ & 1 & & & \\
\hline$\Delta$ No. of cars & $.539^{* * * *}$ & .010 & $-.130^{* * * *}$ & $.083^{* * * *}$ & 1 & & \\
\hline$\Delta$ Car weight & $.066^{* * * *}$ & $-.587^{* * * *}$ & $-.073^{* * * *}$ & .009 & $-.077^{* * * *}$ & 1 & \\
\hline$\Delta$ Car power & $.031^{* * * *}$ & $-.624^{* * * *}$ & $-.057^{* * * *}$ & $.017^{* * *}$ & $-.047^{* * * *}$ & $.665^{* * * *}$ & 1 \\
\hline
\end{tabular}

**** $p<.001 ;{ }^{* *} p<.01 ;{ }^{*} p<.05$ 
Table 4 OLS regression for all households and single-car households with change in driving distance as dependent variable

\begin{tabular}{|c|c|c|c|c|c|c|}
\hline \multirow[b]{2}{*}{ Variable } & \multicolumn{2}{|c|}{ Main sample } & \multicolumn{2}{|c|}{ Single-car households } & \multicolumn{2}{|c|}{ Extended sample ${ }^{*}$} \\
\hline & Estimate & $p$ value & Estimate & $p$ value & Estimate & $p$ value \\
\hline (Intercept) & 466.04 & 0.000 & 542.48 & 0.000 & 559.19 & 0.000 \\
\hline$\Delta$ Fuel efficiency $(\alpha)$ & 39.46 & 0.000 & 31.32 & 0.000 & 56.41 & 0.000 \\
\hline Driving distance baseline $\left(\beta_{1}\right)$ & -0.31 & 0.000 & -0.42 & 0.000 & -0.32 & 0.000 \\
\hline$\Delta$ Income $\left(\beta_{2}\right)$ & 0.05 & 0.000 & 0.03 & 0.000 & 0.03 & 0.000 \\
\hline$\Delta$ No. of cars $\left(\beta_{3}\right)$ & 891.32 & 0.000 & n.a. & n.a. & 964.75 & 0.000 \\
\hline$\Delta$ Car weight $\left(\beta_{4}\right)$ & 0.63 & 0.000 & 0.51 & 0.000 & 0.71 & 0.000 \\
\hline$\Delta$ Car power $\left(\beta_{5}\right)$ & -0.07 & 0.783 & -0.06 & 0.793 & 0.29 & 0.044 \\
\hline Rebound effect & 0.24 & & 0.25 & & 0.30 & \\
\hline$R^{2}$ & 0.42 & & 0.25 & & 0.48 & \\
\hline$N$ & 28,876 & & 17,053 & & 112,442 & \\
\hline
\end{tabular}

* This group includes all households that changed their workplace and/or home address

\section{Discussion}

We followed the distance travelled in a large sample of car owners before and after their change of car. We found no significant bivariate relationship between changes in annual fuel efficiency and driving distance, but when controlling for other factors related to the households' car usage, we found a significant rebound effect of about $24 \%$. Our results are thus in line with previous work, but given the differences in methodological approaches, it is hard to ascertain how and if the results are comparable. It is also worth noting that our estimates are significantly higher than those of De Borger et al. (2016) who also used a similar approach with a set of Danish car owners. The largest difference between the results of these studies appears to be an effect of our adjustment of the type-approval values of fuel efficiency to values that better represent real-world usage of the cars ('Adjusting type-approved values to real-world fuel consumption'). Re-running the model with unadjusted fuel consumption data gives a rebound effect of $15 \%$ which is much closer to the results in De Borger et al. (2016).

We discovered that households who changed to a car labelled as 'green' did not exhibit any significant rebound

Table 5 Summary of OLS regressions for different sub-groups

\begin{tabular}{|c|c|c|c|c|c|c|c|}
\hline Variables & $\begin{array}{l}\text { Efficiency } \\
\text { coefficient }(\alpha)\end{array}$ & Rebound effect & $p$ value & $95 \%$ C.I. lower & $95 \%$ C.I. upper & $p$-diff & $n$ \\
\hline Green labelled car & 2.3 & 0.02 & 0.673 & -0.05 & 0.08 & 0.00 & 5059 \\
\hline Other car & 55.0 & 0.32 & 0.000 & 0.28 & 0.36 & 0.00 & 23,817 \\
\hline Increased fuel efficiency & 23.0 & 0.13 & 0.000 & 0.08 & 0.19 & 0.00 & 16,139 \\
\hline Reduced fuel efficiency & 56.4 & 0.34 & 0.000 & 0.26 & 0.42 & 0.00 & 12,382 \\
\hline Urban & 39.8 & 0.25 & 0.000 & 0.21 & 0.29 & 0.10 & 22,600 \\
\hline Rural & 37.9 & 0.18 & 0.000 & 0.12 & 0.26 & 0.10 & 6276 \\
\hline Multi-person household & 45.0 & 0.24 & 0.000 & 0.19 & 0.28 & 0.81 & 17,754 \\
\hline Single-person household & 29.8 & 0.23 & 0.000 & 0.16 & 0.29 & 0.81 & 11,122 \\
\hline Single-car household & 64.7 & 0.27 & 0.000 & 0.21 & 0.34 & 0.62 & 10,307 \\
\hline Multi-car household & 32.5 & 0.25 & 0.000 & 0.21 & 0.29 & 0.62 & 18,569 \\
\hline Income quartile 1 & 32.8 & 0.22 & 0.000 & 0.14 & 0.30 & 0.72 & 7219 \\
\hline Income quartile 2 & 34.5 & 0.22 & 0.000 & 0.15 & 0.29 & 0.58 & 7219 \\
\hline Income quartile 3 & 44.4 & 0.26 & 0.000 & 0.18 & 0.33 & 0.54 & 7219 \\
\hline Income quartile 4 & 40.6 & 0.21 & 0.000 & 0.15 & 0.28 & 0.68 & 7219 \\
\hline
\end{tabular}


effect, and consequently that the rebound effect for households who bought a 'normal' car is noticeably higher, about $32 \%$ in our sample. As described in the results section, we also analysed households that changed to a 'near green car' (>14 km/l but not labelled as 'green') which showed a rebound effect of $28 \%$. This would seem to indicate that environmental intention is a stronger driving force in this case than the reduced variable cost of driving. It further seems as if the labelling itself has been successful in attracting environmentally motivated households and individuals. This result is particularly interesting and that could warrant further research.

The statistical methods applied in this study differ from those used in previous work on a couple of key points: primarily that we explicitly model regression to the mean, that we compensate for the discrepancy between type-approval and real-world fuel efficiency values, and that we approximate the significance of our coefficient estimates using a bootstrap technique which is insensitive to the exact properties of the residual distribution. The phenomenon of regression to the mean is well-known, and we dealt with it by including the driving distance baseline factor in our regression model. Handling regression to the mean is important in our case because annual distance travelled is not only related to a change in the distance travelled but also to a change in fuel efficiency (by a positive correlation in our data set). This means that households with a higher baseline distance travelled would tend to have both a lower (more negative) change in distance travelled and a higher (more positive) change in fuel efficiency, and vice versa. In other words, it would look like a negative rebound effect.

It should be noted that our approach does not cover all potential mechanisms driving the direct rebound effect. For example, improvements in the fuel efficiency of cars make driving cheaper relative to other modes of transport, which over the longer term could encourage higher levels of car ownership in the population. Such effects cannot be covered using our approach, which only includes current car owners. Lower variable costs related to private transport could also lead to urban sprawl and/or changes to vacation practices as lower costs would encourage people to live further away from where they work. Moreover, increased fuel efficiency could possibly allow for the development of larger and more powerful cars that would cause a different type of rebound effect limiting the improvement in net fuel efficiency itself rather than triggering increasing driving distances. Since these effects can be expected to be longer term adjustments, they are probably not captured to any larger extent by the estimates in this paper.

An important event during the study period was the 2008 financial crisis in the USA that spilled over to the European Union and Sweden in 2009. While the average Swedish GDP per capita was almost identical in the before and after periods of this study (2005-2008 and 20092012), the specific year of 2009 showed a decrease of GDP per capita of $6 \%$ that was recovered in the following years. This may have affected both purchasing decisions and driving behaviour, but we do not expect it to have any major impact on the estimated rebound effect since it was calculated from the cross-sectional differences in the behaviour of all households in the sample who all experienced the same external events.

We believe that the approach used in this study and by De Borger et al. (2016) and Frondel et al. (2008, 2012), to follow a large sample of households, avoids many of the pitfalls of the econometric approaches used in previous research. We hope that studies replicating and improving this approach will be conducted in other countries, for longer time periods and where relocation patterns could also be taken into account. Coulombel et al. (2019) present an interesting approach in this respect, using an integrated transport land use model to estimate different types of rebound effects from ridesharing including modal shift effects, distance effects and relocation effects. Further studies could also try including other car characteristics related to comfort and function, as well as geographical variables to achieve a deeper understanding of the rebound effect and other behavioural dynamics related to the change of car.

\section{Conclusions}

In this paper, we have estimated the direct rebound effect for 28,876 households that replaced their car in 2009. Our approach of following the actual changes in fuel efficiency and travel distances for individual households over time differs from previous econometric approaches for analysing the rebound effects of personal automotive transport. In line with much of the literature on the direct rebound effect, where median estimates have been around $25 \%$ (Sorrell et al. 2009), we found a rebound effect of $24 \%$ in the main sample. Also, when analysing differences in the rebound effect between different groups, households who had changed to a car 
labelled as 'green' did not show any significant rebound effect, while the group who had changed to a 'normal' car showed a rebound effect of around $30 \%$. This could indicate that households that buy a car with improved fuel efficiency for environmental reasons also avoid the economically induced rebound effect. We found no significant differences in rebound effects between different socio-demographic groups.

Acknowledgements We wish to thank the staff at Statistics Sweden MONA database for their support.

Funding information This research was funded by the Swedish Research Council Formas (2014-1179) and the Adlerbert scholarship foundation.

\section{Compliance with ethical standards}

Conflict of interest The authors declare that they have no conflict of interest.

Open Access This article is distributed under the terms of the Creative Commons Attribution 4.0 International License (http:// creativecommons.org/licenses/by/4.0/), which permits unrestricted use, distribution, and reproduction in any medium, provided you give appropriate credit to the original author(s) and the source, provide a link to the Creative Commons license, and indicate if changes were made.

\section{References}

Blair, R. D., Kaserman, D. L., \& Tepel, R. C. (1984). The impact of improved mileage on gasoline consumption. Economic Inquiry, 22(2), 209-217.

Chitnis, M., Sorrell, S., Druckman, A., Firth, S. K., \& Jackson, T. (2014). Who rebounds most? Estimating direct and indirect rebound effects for different UK socioeconomic groups. Ecological Economics, 106, 12-32 Chicago.

Coulombel, N., Boutueil, V., Liu, L., Viguié, V., \& Yin, B. (2019). Substantial rebound effects in urban ridesharing: simulating travel decisions in Paris, France. Transportation Research Part D: Transport and Environment, 71, 110-126.

De Borger, B., Mulalic, I., \& Rouwendal, J. (2016). Measuring the rebound effect with micro data: a first difference approach. Journal of Environmental Economics and Management, 79, $1-17$.

Flachaire, E. (2005). Bootstrapping heteroskedastic regression models: wild bootstrap vs. pairs bootstrap. Computational Statistics \& Data Analysis, 49(2), 361-376.

Freire-Gonzalez, J. (2010). Empirical evidence of direct rebound effect in Catalonia. Energy Policy, 38(5), 2309-2314.

Frondel, M., Peters, J., \& Vance, C. (2008). Identifying the rebound: evidence from a German household panel. Energy Journal, 29(4).
Frondel, M., Ritter, N., \& Vance, C. (2012). Heterogeneity in the rebound effect: further evidence for Germany. Energy Economics, 34(2), 461-467.

Gately, D. (1992). Imperfect price-reversibility of US gasoline demand: asymmetric responses to price increases and declines. The Energy Journal, 179-207.

Goldberg, P. K. (1998). The effects of the corporate average fuel efficiency standards in the US. The Journal of Industrial Economics, 46(1), 1-33.

Greene, D. L. (1992). Vehicle use and fuel economy: how big is the 'rebound' effect? The Energy Journal, 117-143.

Greene, D. L. (2012). Rebound 2007: analysis of US light-duty vehicle travel statistics. Energy Policy, 41, 14-28.

Greene, D. L., Kahn, J. R., \& Gibson, R. C. (1999). Fuel economy rebound effects for U.S. household vehicles. The Energy Journal, 20, 1-31.

Greening, L. A., Greene, D. L., \& Difiglio, C. (2000). Energy efficiency and consumption - the rebound effect - a survey. Energy policy, 28(6-7),389-401.

Haughton, J., \& Sarkar, S. (1996). Gasoline tax as a corrective tax: estimates for the United States, 1970-1991. The Energy Journal, 103-126.

ICCT. (2015). From laboratory to road a 2015 update of official and "real-world" fuel consumption and $\mathrm{CO}_{2}$ values for passenger cars in Europe ICCT white paper.

Jones, C. T. (1993). Another look at U.S. passenger vehicle use and the 'rebound' effect from improved fuel efficiency. The Energy Journal, 14, 99-110.

Mayo, J. W., \& Mathis, J. E. (1988). The effectiveness of mandatory fuel efficiency standards in reducing the demand for gasoline. Applied Economics, 20(2), 211-219.

Milne, G., \& Boardman, B. (2000). Making cold homes warmer: the effect of energy efficiency improvements in low-income homes A report to the Energy Action Grants Agency Charitable Trust. Energy Policy, 28(6), 411-424.

Moshiri, S., \& Aliyev, K. (2017). Rebound effect of efficiency improvement in passenger cars on gasoline consumption in Canada. Ecological Economics, 131, 330-341.

Ntziachristos, L., Mellios, G., Tsokolis, D., Keller, M., Hausberger, S., Ligterink, N. E., \& Dilara, P. (2014). In-use vs. type-approval fuel consumption of current passenger cars in Europe. Energy Policy, 67, 403-411.

OECD/IEA. (2017). Energy technology perspectives 2017: catalysing energy technology transformations. Paris.

Pacala, S., \& Socolow, R. (2004). Stabilization wedges: solving the climate problem for the next 50 years with current technologies. Science, 305(5686), 968-972.

Paternoster, R., Brame, R., Mazerolle, P., \& Piquero, A. (1998). Using the correct statistical test for the equality of regression coefficients. Criminology, 36(4), 859-866.

Puller, S. L., \& Greening, L. A. (1999). Household adjustment to gasoline price change: an analysis using 9 years of US survey data. Energy Economics, 21(1), 37-52.

Schimek, P. (1996). Gasoline and travel demand models using time series and cross-section data from United States. Transportation Research Record: Journal of the Transportation Research Board, 1558, 83-89.

Schipper, L., \& Johansson, O. (1997). Measuring long-run automobile fuel demand; separate estimations of vehicle stock, mean fuel intensity, and mean annual driving distance. Journal of Transport Economics and Policy, 31(3), 277-292. 
Small, K. A., \& Van Dender, K. (2005). A study to evaluate the effect of reduced greenhouse gas emissions on vehicle miles traveled. California Environmental Protection Agency, Air Resources Board, Research Division.

Small, K. A., \& Van Dender, K. (2007). Fuel efficiency and motor vehicle travel: the declining rebound effect. The Energy Journal, 28, 25-51.

Sorrell, S., \& Dimitropoulos, J. (2008). The rebound effect: microeconomic definitions, limitations and extensions. Ecological Economics, 65(3), 636-649.

Sorrell, S., Dimitropoulos, J., \& Sommerville, M. (2009). Empirical estimates of the direct rebound effect: a review. Energy Policy, 37(4), 1356-1371.

Sprei, F., \& Karlsson, S. (2013). Energy efficiency versus gains in consumer amenities - an example from new cars sold in Sweden. Energy Policy, 53, 490-499.

Stapleton, L., Sorrell, S., \& Schwanen, T. (2016). Estimating direct rebound effects for personal automotive travel in Great Britain. Energy Economics.

Swedish Transport Administration. (2012). Report (in Swedish): Index över nya bilars klimatpåverkan 2012 i riket, länen och kommunerna inkl. nyregistrerade, kommunägda fordon och dess klimatpåverkan. Internet resource available at: https://trafikverket.ineko.se/Files/sv-SE/11407 /RelatedFiles/2013_053_index_over_nya_bilars klimatpaverkan_2012_i_riket_lanen_och_kommunerna.pdf. Accessed 16 Sept 2019.

Wang, H., Zhou, D. Q., Zhou, P., \& Zha, D. L. (2012). Direct rebound effect for passenger transport: empirical evidence from Hong Kong. Applied Energy, 92(April 2012), 162-167.

West, S. E. (2004). Distributional effects of alternative vehicle pollution control policies. Journal of Public Economics, 88(3), 735-757.

Wheaton, W. C. (1982). The long-run structure of transportation and gasoline demand. The Bell Journal of Economics, 13, 439-454.

Wirl, F. (1997). The economics of conservation programs. Berlin: Springer Science \& Business Media.

Publisher's note Springer Nature remains neutral with regard to jurisdictional claims in published maps and institutional affiliations. 